\title{
Martine Creac'h, Poussin pour mémoire. Bonnefoy, Du Bouchet, Char, Jaccottet, Simon
}

\section{Elisa Bricco}

\section{Q OpenEdition}

1 Journals

\section{Edizione digitale}

URL: http://journals.openedition.org/studifrancesi/35186

DOI: 10.4000/studifrancesi.35186

ISSN: 2421-5856

\section{Editore}

Rosenberg \& Sellier

\section{Edizione cartacea}

Data di pubblicazione: 1 novembre 2005

Paginazione: 451

ISSN: 0039-2944

\section{Notizia bibliografica digitale}

Elisa Bricco, «Martine Creac'h, Poussin pour mémoire. Bonnefoy, Du Bouchet, Char, Jaccottet, Simon»,

Studi Francesi [Online], 146 (XLIX | II) | 2005, online dal 30 novembre 2015, consultato il 18 avril 2021.

URL: http://journals.openedition.org/studifrancesi/35186 ; DOI: https://doi.org/10.4000/studifrancesi. 35186

Questo documento è stato generato automaticamente il 18 avril 2021.

\section{(c) (1)}

Studi Francesi è distribuita con Licenza Creative Commons Attribuzione - Non commerciale - Non opere derivate 4.0 Internazionale. 
Martine Creac'h, Poussin pour mémoire. Bonnefoy, Du Bouchet, Char, Jaccottet, Simon

Elisa Bricco 


\section{NOTIZIA}

MARTINE CREAC'H, Poussin pour mémoire. Bonnefoy, Du Bouchet, Char, Jaccottet, Simon, P.U.

Vincennes «Essais et Savoirs», 2004, pp. 171.

1 Per lungo tempo considerato il campione della pittura figurativa, Nicolas Poussin aveva esortato i propri commentatori a una lettura approfondita delle tele: egli auspicava infatti una lettura che andasse al di là della semplice rappresentazione, per coglierne le verità nascoste. Questa lettura non doveva però essere pura interpretazione, perché il passaggio da un sistema semiotico all'altro avrebbe causato una sicura perdita del significato dell'opera. Com'è possibile allora, oggi, a distanza di tre secoli, leggere e comprendere appieno l'opera del pittore? Alla domanda rispondono alcuni autori contemporanei che si sono cimentati nella lettura, o meglio nel dialogo con Poussin, seguendo itinerari diversi, sollecitati da una pittura tanto figurativa quanto ricca e attuale.

2 Simon e Char, e poi Bonnefoy, du Bouchet e Jaccottet si sono avvicinati alla pittura di Poussin dopo aver vissuto una medesima esperienza della guerra, e soprattutto a partire da una sensibilità che vedeva l'ideale di perfezione e universalismo latino in contrapposizione con la dismisura e il nazionalismo tedesco. L'autrice mette l'accento su questi tratti che accomunano gli autori tra loro nella percezione dell'arte come manifestazione alta del pensiero e della mente, con la quale gli scrittori prediligono dialogare. $\mathrm{E}$ il loro dialogo si farà via via più soggettivo e più personale perché tutti cercano e trovano in Poussin un interlocutore privilegiato, tutti leggono nella sua arte la loro propria poetica. 